\title{
Relação entre a gestão do conhecimento e a gestão da qualidade sob a ótica do modelo GCFQ: análise em uma empresa de TI de Foz do IguaçU
}

\section{Relationship between knowledge management and quality management from the perspective of GCFQ model: analysis on Information Technology's company}

\author{
HUGO ALEXANDRE SOUZA RIBEIRO* \\ EDUARDO MOREIRA**
}

\section{RESUMO}

Um número crescente de pesquisas tem buscado avaliar, de maneira isolada, a gestão do conhecimento (GC) e a gestão da qualidade (GQ) nos mais diversos segmentos empresariais. Contudo, ainda são raros os estudos que associam tais dimensões como fatores determinantes do desempenho organizacional. Nas empresas de Tecnologia da Informação (TI), a identificação e avaliação desses elementos mostra-se iminente em virtude da necessidade de planejamento adaptativo, flexibilidade e rápida resposta às mudanças, tendo ainda relação direta com a competitividade e a sobrevivência. Nesse contexto, sob o enfoque do arquétipo proposto por Batista (2008), o objetivo deste estudo foi analisar a relação entre a GC e a GQ em uma empresa de TI do município de Foz do Iguaçu (PR), identificando as dimensões

* Universidade Estadual do Oeste do Paraná campus Foz do Iguaçu. Mestrando em Tecnologias, Gestão e Sustentabilidade. Administrador com MBA em Gerenciamento de Projetos e Administração Empresarial e Financeira. hugoasr@gmail.com.

** Universidade Estadual do Oeste do Paraná campus Foz do Iguaçu. Graduação em Engenharia Mecânica pela Universidade Federal de Itajubá (1977), Mestrado em Engenharia Mecânica pela Universidade Federal de Itajubá (1987) e Doutorado em Engenharia de Produção pela Universidade Federal de Santa Catarina (2002). moreiraarquivo@gmail.com. 
mais relevantes para o modelo organizacional. Dados obtidos por meio de uma abordagem mista (qualitativa e quantitativa) evidenciaram uma complementaridade entre as ações de GQ e GC; no entanto, revelaram também a necessidade de estratégias mais efetivas relacionadas às práticas de gestão, posto que todos os constructos analisados apresentaram pontuações medianas. Palavras-chave: Tecnologia da Informação; competitividade; dimensões; gestão da qualidade; gestão do conhecimento.

\section{AbTract}

Several studies have evaluated, in isolation, knowledge management $(\mathrm{KM})$ and quality management $(\mathrm{QM})$ in the most diverse business segments. However, there are still few studies that associate such dimensions as determinants of organizational performance. In the Information Technology (IT) companies, the identification and evaluation of these elements is urgent because of the need for adaptive planning, flexibility and rapid response to changes, and a direct relation with the competitiveness and survival. In this context, based on the model proposed by Batista (2008), the objective of this study was to analyze the relationship between GC and GQ in an IT company in the Foz do Iguaçu city, identifying which dimensions are most relevant to the organization. Data collected through a mixed approach (qualitative and quantitative) showed a complementarity between KM and QM actions; however, also revealed the need for more effective strategies related to management practices, since all the constructs analyzed presented medium scores.

Keywords: Information Technology; competitiveness; dimensions; quality management; knowledge management.

\section{INTRODUÇÃo}

Com o aumento da competitividade empresarial e do nível de exigência dos consumidores, as empresas de Tecnologia da Informação (TI) têm buscado modelos de referência que auxiliem no processo de desenvolvimento de software e hardware e na qualidade gerencial como um todo.

Nesse sentido, a gestão da qualidade (GQ) e a gestão do conhecimento (GC) emergem como práticas fundamentais para a sobrevivência organizacional, fornecendo conhecimentos, ferramentas e 
técnicas importantes na condução de processos e projetos. Todavia, a avaliação conjunta desses elementos ainda é considerada incipiente na literatura, podendo influenciar negativamente o gerenciamento interno da empresa, posto que a medição é essencial para a eficácia organizacional (CANTNER; JOEL; SCHMIDT, 2011).

Assim, considerando que as práticas de GC e GQ agregam riqueza e valor (SVEIBY, 2001), analisar a interface entre esses elementos pode representar uma vantagem competitiva sustentável ou assegurar um desempenho elevado e duradouro (BENNET; BENNET, 2004). No caso das empresas de TI, tal interdependência pode indicar a oportunidade de conquistar novos clientes e potencializar seu poder de mercado.

Nessa perspectiva, tendo como ponto de partida o modelo de Batista (2008), que aborda os principais constructos de gestão da qualidade total (GQT), critérios de excelência da Fundação Nacional da Qualidade (FNQ), modelo de excelência do Prêmio Malcolm Baldrige e ciclos e modelos de GC, este estudo busca responder à seguinte problemática: qual a relação entre GC e a GQ em uma empresa de TI de Foz do Iguaçu? Para tanto, pretende-se identificar as principais práticas de GC e GQ adotadas pela companhia e analisar os pontos de convergência existentes entre esses elementos, verificando quais dimensões do referido modelo apresentam maior relevância para ela.

Isso posto, este artigo está estruturado em três seções que se sucedem a esta introdução. Na Seção 1, apresenta-se síntese sobre o conceito de GQ e GC. A Seção 2 traz os procedimentos metodológicos adotados e a Seção 3, a análise dos dados e interpretação dos resultados. Por fim, há as considerações finais, limitações e sugestões para pesquisas futuras.

\section{FUndamentação TEÓRICA}

Nesta seção apresentam-se conceitos sobre gestão da qualidade, gestão do conhecimento e interface entre esses elementos por meio do modelo teórico-prático desenvolvido por Batista (2008).

\subsection{Gestão da qualidade}

A evolução do conceito de gestão da qualidade sofreu mudanças importantes desde o século XIX. No início, a preocupação estava 
em inspecionar produtos da linha de produção; a partir da década de 1920, o foco passou a ser a prevenção (CIERCO et al., 2003) por meio do controle estatístico de processo e do ciclo PDCA (planejar, executar, verificar e agir).

Contudo, foi apenas a partir da década de 1950, com trabalhos de Juran, Deming e Feigenbaum, que as práticas de GQ foram disseminadas, principalmente no Japão, e o conceito ampliou-se, passando a significar a gestão da organização como um todo e não apenas a qualidade dos processos e produtos (BATISTA, 2008). Além disso, com o advento de prêmios nacionais da qualidade nos anos de 1980, os atributos do conceito de GQ foram incorporados aos critérios de excelência de gestão e passaram a ser adotados por milhares de empresas em todo o mundo.

De acordo com a International Organization for Standardization (ISO), qualidade é o grau de satisfação de requisitos dados por um conjunto de características intrínsecas. Campos (1999) ratifica essa conceituação, mas acrescenta que quem define a qualidade é o consumidor. Nesse contexto, o cliente é a pessoa mais importante (DEMING, 1986), e a qualidade permite o aumento da satisfação, torna os produtos e serviços vendáveis, faz frente à competição, aumenta a fatia de mercado, etc. (JURAN, 1989).

Nesse âmbito, "a qualidade deve ser encarada de forma estratégica pela organização" (PALADINI, 2005, p. 27). Desse modo, a GQ, combinada a uma estrutura operacional de trabalho adequada, requer maior integração tanto vertical - diretrizes estratégicas quanto horizontal - processos e procedimentos (MARTINS; COSTA NETO, 1998). Sob esse enfoque, tal estrutura pode ser operacionalizada por meio de ferramentas. O Quadro 1 apresenta síntese das principais ferramentas de qualidade utilizadas pelas organizações. 
Quadro 1: Resumo das principais ferramentas de gestão da qualidade

\begin{tabular}{|c|c|}
\hline Ferramenta & Descrição resumida \\
\hline $\begin{array}{l}\text { Diagrama de } \\
\text { Ishikawa }\end{array}$ & $\begin{array}{l}\text { Utilizado para identificar as causas relacionadas a deter- } \\
\text { minado problema (efeito) }\end{array}$ \\
\hline Ciclo PDCA & $\begin{array}{l}\text { Utilizado para controlar e melhorar continuamente os } \\
\text { processos empresariais. As letras significam: } \mathrm{P}(\text { plan }= \\
\text { planejar }), \mathrm{D}(\text { do = executar }), \mathrm{C}(\text { check = verificar }) \text { e A }(\text { act }= \\
\text { administrar })\end{array}$ \\
\hline $\begin{array}{l}\text { Diagrama de } \\
\text { Paretto }\end{array}$ & $\begin{array}{l}\text { Utilizado para visualizar quais causas produzem efeitos } \\
\text { maiores em determinada situação }\end{array}$ \\
\hline Trilogia de Juran & $\begin{array}{l}\text { Forma de gerenciamento da qualidade que envolve ativi- } \\
\text { dades de planejamento, controle e melhoria contínua da } \\
\text { qualidade utilizada para gerenciar mudanças e prevenir } \\
\text { riscos }\end{array}$ \\
\hline Benchmarking & $\begin{array}{l}\text { Utilizado para comparação com as melhores organiza- } \\
\text { ções, processos e/ou produtos }\end{array}$ \\
\hline $\begin{array}{l}\text { Gerenciamento } \\
\text { pelas diretrizes }\end{array}$ & $\begin{array}{l}\text { Utilizado para alinhar a organização em torno de seus } \\
\text { objetivos estratégicos, desdobrando os objetivos gerais } \\
\text { em específicos de modo participativo }\end{array}$ \\
\hline Brainstorming & $\begin{array}{l}\text { Utilizado para gerar ideias espontaneamente a respeito } \\
\text { de determinado assunto }\end{array}$ \\
\hline $5 \mathrm{~W}+2 \mathrm{H}$ & $\begin{array}{l}\text { Utilizado para o planejamento de atividades ou para } \\
\text { conhecimento de determinado processo. As letras signifi- } \\
\text { cam: Who (quem), What (que/qual), When (quando), Where } \\
\text { (onde) Why (por que), How (como) e How much (quanto } \\
\text { custa) }\end{array}$ \\
\hline Fluxograma & $\begin{array}{l}\text { Ferramenta utilizada para representação gráfica do fluxo } \\
\text { de um processo }\end{array}$ \\
\hline $\begin{array}{l}\text { Times da quali- } \\
\text { dade }\end{array}$ & $\begin{array}{l}\text { Equipes de trabalho formadas para assegurar o desen- } \\
\text { volvimento e a implementação do sistema de gestão da } \\
\text { qualidade na empresa }\end{array}$ \\
\hline $\begin{array}{l}\text { Círculo de Con- } \\
\text { trole de Qualida- } \\
\text { de - CCQ }\end{array}$ & $\begin{array}{l}\text { Grupo pequeno destinado a conduzir de forma voluntá- } \\
\text { ria atividades de controle de qualidade dentro da mesma } \\
\text { área de trabalho }\end{array}$ \\
\hline $\begin{array}{l}\text { Lista de verifica- } \\
\text { ção }\end{array}$ & $\begin{array}{l}\text { Utilizada para levantamento de dados ou para verificar } \\
\text { se todos os itens planejados foram executados }\end{array}$ \\
\hline Matriz GUT & $\begin{array}{l}\text { Utilizada para a priorização de problemas. As letras sig- } \\
\text { nificam: G (gravidade), U (urgência) e T (tendência) }\end{array}$ \\
\hline
\end{tabular}

Fonte: Adaptado de Kurta (2007). 
Além dessas ferramentas, no segmento de TI há uma importante referência no campo da GQ: o MPS.BR. O Programa de Melhoria de Processo do Software Brasileiro é uma iniciativa criada e gerenciada pela Associação para Promoção da Excelência do Software Brasileiro (SOFTEX) com o objetivo de promover a melhoria da qualidade e da produtividade de soluções e serviços de software de acordo com os padrões de qualidade internacional (KOSCIANSKI; SOARES, 2007).

$\mathrm{O}$ modelo, representado por letras em ordem decrescente, possui sete níveis de maturidade:

i) parcialmente gerenciado $(G)$ - assinala pontos de melhoria de processo em gerenciamento de projetos e de requisitos;

ii) gerenciado $(\mathrm{F})$ - apresenta melhorias de processo nas áreas de aquisições, configuração, portfólio de projetos, garantia da qualidade e medição;

iii) parcialmente definido (E) - indica melhorias na avaliação e no processo organizacional, gerenciamento de recursos humanos e reutilização;

iv) largamente definido (D) - sugere a necessidade de correções no desenvolvimento de requisitos, integração do produto, projeto e construção do produto e validação;

v) definido (C) - indica evolução no gerenciamento de decisões, desenvolvimento para reutilização e gerência de riscos;

vi) gerenciado quantitativamente (B) - sugere evolução do gerenciamento de projeto; e

vii)em otimização (A) - indica que a organização deve buscar otimizar o processo implantado (CUNHA; DIAS; RESENDE JUNIOR, 2011).

Nesse sentido, o progresso e o alcance de determinado nível de maturidade do MPS.BR são obtidos quando atendidos os propósitos e os resultados esperados dos respectivos processos e atributos estabelecidos para aquele nível.

Entretanto, para que uma empresa implante e mantenha um programa de qualidade, independentemente de qual seja, é necessário que o conhecimento organizacional esteja formalizado, registrado e sirva de parâmetro para o processo decisório. 


\subsection{Gestão do conhecimento}

Diferentemente da GQ, a gestão do conhecimento apresenta histórico mais recente: teve início em 1986, quando Karl Wiig utilizou pela primeira vez o conceito de GC (DALKIR, 2005). A partir dessa data, autores como Sveiby (2001), Senge (1990), Nonaka e Takeuchi (1997) e Davenport (1998) passaram a discuti-la; entretanto, a temática só adquiriu maior reconhecimento a partir dos anos de 2000, período em que houve a publicação de centenas de artigos científicos (BATISTA, 2008).

Embora existam diversas definições de conhecimento, parece haver consenso sobre dois tipos dele: o tácito e o explícito. O primeiro é o que está na mente do indivíduo e que é de difícil transferência; o segundo diz respeito aquele registrado, documentado e, portanto, mais facilmente compartilhado. Davenport e Prusak (2003, p. 14) ratificam esse conceito ao mencionar que "o conhecimento é uma mistura fluida de experiência condensada, valores, informação contextual e insight experimentado", o qual proporciona uma estrutura para a incorporação e avaliação de um ciclo contínuo de GC.

Atualmente, o conhecimento é considerado o ativo mais importante das organizações, pois, conforme afirma Sveiby (2001), esse recurso é capaz de assegurar a vantagem competitiva. Nesse cenário, a GC, assim como a GQ, deve ser vista como um grande processo sistemático e explícito de atividades, práticas, programas e políticas relacionadas ao conhecimento da organização (CLARKE, 2006). O Quadro 2 apresenta um resumo das principais práticas de GC. 
Quadro 2: Resumo das principais práticas de gestão do conhecimento

\begin{tabular}{|c|c|}
\hline Prática & Descrição resumida \\
\hline $\begin{array}{l}\text { Aprendizagem } \\
\text { organizacional }\end{array}$ & $\begin{array}{l}\text { Refere-se ao aprendizado coletivo, por meio do racio- } \\
\text { cínio sistêmico, domínio pessoal, modelos mentais, } \\
\text { visão compartilhada e aprendizado em equipe (SEN- } \\
\text { GE, 1990) }\end{array}$ \\
\hline Benchmarking & $\begin{array}{l}\text { Processo contínuo e sistemático de avaliação de pro- } \\
\text { dutos, serviços ou processos de organizações identifi- } \\
\text { cadas como líderes (SPENDOLINI, 1994) }\end{array}$ \\
\hline Coaching & $\begin{array}{l}\text { Processo desenvolvido pelo gestor com o objetivo } \\
\text { de treinar e orientar o funcionário conforme as suas } \\
\text { necessidades no local de trabalho (MINOR, 1997) }\end{array}$ \\
\hline $\begin{array}{l}\text { Comunicação } \\
\text { institucional }\end{array}$ & $\begin{array}{l}\text { Envolve todos os meios adequados para que as infor- } \\
\text { mações possam fluir dentro do ambiente de trabalho } \\
\text { (MEDEIROS, 1998) }\end{array}$ \\
\hline $\begin{array}{l}\text { Comunidades de } \\
\text { prática }\end{array}$ & $\begin{array}{l}\text { Grupos que compartilham e gerenciam o conhecimen- } \\
\text { to sobre tópicos ou disciplinas nas quais as pessoas } \\
\text { têm interesse comum. (BEJARANO et al., 2006) }\end{array}$ \\
\hline $\begin{array}{l}\text { Educação corpo- } \\
\text { rativa }\end{array}$ & $\begin{array}{l}\text { Criação de ambiente e cultura organizacional cujos } \\
\text { princípios e valores disseminados sejam propícios } \\
\text { para processos de aprendizagem ativa e contínua, } \\
\text { favoreçam a formação e a atuação de lideranças e } \\
\text { estimulem posturas do autodesenvolvimento (ÉBOLI, } \\
\text { 2005) }\end{array}$ \\
\hline $\begin{array}{l}\text { Gestão de compe- } \\
\text { tências }\end{array}$ & $\begin{array}{l}\text { Compreende a implementação de planos de gerencia- } \\
\text { mento com o objetivo de desenvolver competências } \\
\text { específicas nos colaboradores (GIACOBBO et al., 2005) }\end{array}$ \\
\hline $\begin{array}{l}\text { Relacionamento } \\
\text { com os clientes }\end{array}$ & $\begin{array}{l}\text { Refere-se a uma rede de processos interligados na } \\
\text { organização para ouvir e atender aos clientes (FRAN- } \\
\text { CINI, 2002) }\end{array}$ \\
\hline $\begin{array}{l}\text { Inteligência com- } \\
\text { petitiva }\end{array}$ & $\begin{array}{l}\text { Instrumento utilizado por empresas para identificar, } \\
\text { coletar, sistematizar e interpretar informações rele- } \\
\text { vantes sobre seu ambiente (CANONGIA et al., 2004) } \\
\end{array}$ \\
\hline $\begin{array}{l}\text { Lições aprendi- } \\
\text { das }\end{array}$ & $\begin{array}{l}\text { Representam a essência da experiência adquirida em } \\
\text { um projeto ou cargo específico, visando a aprender } \\
\text { com os sucessos e erros (PROBST; RAUB; ROMHAR- } \\
\text { DT, 2002) }\end{array}$ \\
\hline
\end{tabular}




\begin{tabular}{|l|l|}
\hline Prática & Descrição resumida \\
\hline $\begin{array}{l}\text { Mapeamento de } \\
\text { conhecimentos }\end{array}$ & $\begin{array}{l}\text { Registro do conhecimento organizacional por meio } \\
\text { de uma árvore de conhecimento na qual são descritos } \\
\text { os fluxos e relacionamentos (CARDOSO; MORETO; } \\
\text { SILVA, 2001) }\end{array}$ \\
\hline $\begin{array}{l}\text { Mapeamento de } \\
\text { processos }\end{array}$ & $\begin{array}{l}\text { Instrumento representado por um mapa cujo objetivo } \\
\text { é modificar e otimizar o processo original (KLOTZ et } \\
\text { al., 2008) }\end{array}$ \\
\hline Melhores práticas & $\begin{array}{l}\text { Práticas que produzem resultados excelentes em } \\
\text { outra situação e que podem ser adaptados para uma } \\
\text { situação semelhante (O'DELL; GRAYSON, 2000) }\end{array}$ \\
\hline $\begin{array}{l}\text { Memória organi- } \\
\text { zacional }\end{array}$ & $\begin{array}{l}\text { Conjunto de conhecimentos organizados em função } \\
\text { de tudo o que a empresa vivenciou e das condições } \\
\text { do ambiente (SOLTERO, 2003) }\end{array}$ \\
\hline Mentoring & $\begin{array}{l}\text { Prática de orientação utilizada para converter o co- } \\
\text { nhecimento tácito em explícito (FRANCINI, 2002) }\end{array}$ \\
\hline $\begin{array}{l}\text { Normalização e } \\
\text { padronização }\end{array}$ & $\begin{array}{l}\text { Atividade que estabelece padrões para utilização } \\
\text { diante de determinado contexto (ALMACINHA, } \\
\text { 2005) }\end{array}$ \\
\hline $\begin{array}{l}\text { Portais Corpora- } \\
\text { tivos }\end{array}$ & $\begin{array}{l}\text { Instrumento utilizado para fornecer informações } \\
\text { específicas do negócio aos clientes (REYNOLS; KOU- } \\
\text { LOPOULOS, 1999). }\end{array}$ \\
\hline
\end{tabular}

Fonte: Elaborado pelos autores.

Sob esse enfoque, em virtude de o sistema de GQ ser mais facilmente identificado e formalizado do que a GC, pesquisar a influência de um sobre o outro é altamente relevante (KURTA; CARVALHO; KOVALESKI, 2004). Nesse âmbito, o estudo de modelos que avaliem o desempenho em diferentes critérios de GQ e GC pode conduzir à excelência empresarial.

\subsection{Interface da gestão da qualidade com a gestão do conhe- cimento}

De acordo com Valls (2004), existe uma sinergia entre a GC e GQ. Silva (2002) corrobora ao afirmar que a utilização de sistemas de qualidade facilita a implantação da GC nas organizações, uma vez que os pontos de melhoria são identificados e monitorados mais facilmente. Por sua vez, Kurta, Carvalho e Kovaleski (2004) 
sintetizam que os conceitos de GC relativos ao compartilhamento de informações, à aprendizagem e ao capital intelectual, quando aplicados em um sistema de GQ, podem conduzir a melhor aproveitamento de todas as dimensões organizacionais, transformando o sistema em um ciclo de melhoria contínua.

Sob essa perspectiva, embora existam diversos modelos para avaliar GC - Modelo Espiral do Conhecimento (Nonaka e Takeuchi, 1997), Modelo de Boisot (1998), Probst, Raub e Romhardt (2002), Choo (2004), Bennet e Bennet (2004) e GQ - Prêmio Nacional da Qualidade (PNQ, 1992), Prêmio Malcolm Baldrige (1987), Normas ISO etc. -, ainda são raras as referências teóricas que ponderam sobre essas duas práticas conjuntamente.

Nesse âmbito, Batista (2008) desenvolveu um modelo de gestão do conhecimento com foco na qualidade (GCFQ) baseado nos constructos da gestão da qualidade total, nos critérios de excelência da gestão do PNQ e nos processos de GC. Desse modo, o arquétipo desenvolvido considera oito dimensões organizacionais - liderança; estratégias e planos; clientes; sociedade; informações e conhecimento; pessoas; processos; e resultados -, cujo objetivo é alcançar qualidade, obter excelência gerencial e, consequentemente, melhorar o desempenho da empresa.

O primeiro constructo diz respeito à liderança, ou seja, a maneira pela qual "a direção gerencia os conhecimentos relativos ao cliente, ao mercado, à sociedade, ao desempenho organizacional e aos fundamentos de excelência em gestão" (BATISTA, 2008, p. 175). Logo, a importância do líder é indelegável nesse processo (CAMPOS, 1999), e sua responsabilidade é entender o que é necessário para tomar a melhor decisão (CROSBY, 1979), otimizando continuamente todo o sistema de gestão.

A dimensão "estratégia e planos" refere-se ao modo pelo qual a organização gerencia o conhecimento acerca de seu setor de atuação, ambiente interno e estratégias (BATISTA, 2008), visando a atingir um desempenho superior (CAMPOS, 1999). O constructo "clientes" relaciona-se com a maneira pela qual são identificadas as necessidades e expectativas dos clientes (FNQ, 2016), com foco no atingimento do maior grau de satisfação destes em relação aos produtos e serviços oferecidos pela empresa (BATISTA, 2008). 
Na sequência, a dimensão "sociedade" denota uma preocupação organizacional com os impactos sociais dos produtos e com a interação da empresa com a comunidade. O critério também diz respeito à ética institucional, cumprimento de leis e preservação dos ecossistemas (FNQ, 2016). Já o constructo "informações e conhecimento" disponibiliza informações aos usuários, capta as dos concorrentes e identifica os ativos mais importantes para desenvolver o negócio e melhorar o desempenho (BATISTA, 2008).

A dimensão "pessoas" refere-se à maneira como o conhecimento acerca da força de trabalho é gerenciado. Para Deming (1986), essa preocupação é um dos princípios da transformação organizacional e deve centrar-se em fornecer aos colaboradores oportunidades de educação e capacitação, fazendo com que estes se transformem nos "melhores do mundo" e tenham orgulho em trabalhar na empresa (CAMPOS, 1999). No que tange à dimensão "processos", esta se refere a como a organização gerencia o conhecimento sobre seus processos de apoio e finalísticos (BATISTA, 2008), visto que a execução e gerenciamento possibilita agregação de valor para o cliente e o aperfeiçoamento do relacionamento com os fornecedores (FNQ, 2016).

Por fim, o constructo "resultados" examina o desempenho da empresa como um todo, isto é, a melhoria contínua dos processos, produtos e serviços (DEMING, 1986). Destarte, focando em variáveis de eficiência, eficácia e inovação, os resultados obtidos por ela são avaliados em todas as outras sete dimensões.

Nesse contexto, a verificação dos constructos de GC e GQ que mais impactam o desempenho organizacional mostra-se fundamental para avaliar se os efeitos gerados estão em consonância com as metas estabelecidas e se há necessidade de correções de rumo e/ou reforço de ações já implementadas na empresa. Desse modo, a GC e GQ podem contribuir ainda para a criação, manutenção e reformulação de uma reputação favorável, pois, conforme afirmam Meyrs e Reynolds (1972), convém ao público estar no "time vencedor", isto é, naquele que oferece maior valor. 


\section{Procedimentos metodológicos}

Para responder à problemática central, a abordagem escolhida foi a mista (qualitativa e quantitativa), uma vez que permite observar um fenômeno sob diferentes perspectivas. Nesse sentido, o estudo classifica-se como descritivo, visto que os fatos gerados são observados, registrados, analisados, classificados e interpretados (ANDRADE, 2002).

Para responder aos dois primeiros objetivos específicos do estudo de identificar as principais práticas de GC e GQ executadas na empresa, utilizaram-se, como instrumentos de coleta de dados, o estudo de caso e a pesquisa documental. De acordo com Yin (1994), o estudo de caso é a estratégia mais apropriada quando se procura responder às questões "como" e "por quê". Por sua vez, a pesquisa documental permite uma análise dos fatos a partir de documentos, escritos ou não, constituindo o que se denomina de fontes primárias (MARCONI; LAKATOS, 2003).

Para mensurar a convergência entre os elementos de GC e GQ, terceiro objetivo, utilizou-se questionário do modelo GCFQ proposto por Batista (2008), formado por 55 questões divididas em oito dimensões (liderança; estratégias e planos; clientes; sociedade; informações e conhecimento; pessoas; processos; e resultados). Por meio de uma escala do tipo Likert de 5 pontos, em que 1 representa "discordo totalmente" e 5, "concordo totalmente", buscou-se identificar as práticas de gestão mais ou menos executadas na empresa.

A pesquisa foi aplicada eletronicamente via Google Formulários durante os dias 10 e 21 de junho de 2016 aos colaboradores de uma empresa de TI do município de Foz do Iguaçu (PR). De um universo de 26 pessoas, aderiram ao estudo um montante de 21 , o que equivale a $81 \%$ do total.

Os dados obtidos foram tabulados no software Microsoft Excel e analisados por meio da triangulação de dados (primários e secundários), garantindo assim maior rigor, riqueza e profundidade à pesquisa (YIN, 1994).

\section{Apresentação e ANÁlise dos RESUltados}

A seguir é caracterizada a organização do objeto de estudo, assim como as principais práticas de GQ e GC adotadas pela empresa e a interface entre esses elementos. 


\subsection{Caracterização da empresa de TI}

A empresa de TI pesquisada foi criada em 2005 a partir da união de quatro instituições. Tal associação foi planejada para otimizar experiências e conquistar maior poder de mercado, visando a transformar a organização em referência na criação e desenvolvimento de soluções tecnológicas.

Instalada no município de Foz do Iguaçu, a empresa dispõe de um time de 26 colaboradores graduados, especialistas e mestres nas áreas de Administração, Ciência da Computação, Sistemas de Informação e Engenharia de Software.

Com mais de dez anos no mercado, a companhia já executou mais de 600 projetos nos segmentos energético, industrial, hoteleiro, bancário, comercial e militar. Outrossim, também já conquistou prêmios importantes de subvenção em nível nacional - Primeira Empresa Inovadora (PRIME), P\&D Eletrobrás e TECNOVA FINEP e estadual - Programa de Apoio à Pesquisa em Empresas (PAPPE).

\subsection{Correlações entre a gestão da qualidade e a gestão do conhecimento}

Na sequência, efetivou-se a caracterização do perfil da amostra do estudo. Do total de 21 amostras válidas, constatou-se heterogeneidade quanto ao cargo dos respondentes, posto que foram identificadas sete funções diferentes: diretores (9,52\%), gerentes/coordenadores de projetos (9,52\%), analistas desenvolvedores $(38,10 \%)$, analistas de sistemas $(28,58 \%)$, design gráfico $(4,76 \%)$, analista da qualidade $(4,76 \%)$ e estagiária $(4,76 \%)$.

No que tange ao tempo de trabalho, $71 \%$ afirmaram atuar na organização entre 1 e 3 anos, 19\% há mais de 3 anos, e 10\% estão há menos de 1 ano. Em relação às experiências prévias dos colaboradores com os constructos GC e GQ, verifica-se que $86 \%$ dos respondentes não tiveram contatos anteriores com essas temáticas. Tais índices mostraram-se, em parte, contraditórios, já que ao mesmo tempo que denotam que a grande maioria dos colaboradores possui condições de conhecer as estratégias e processos de GC e GQ da empresa em virtude do tempo de atuação, é possível que estes não reconheçam tais práticas em razão do desconhecimento prévio acerca deles.

Caracterizado o perfil, iniciou-se o cumprimento do primeiro objetivo deste estudo, a saber, identificar as práticas de gestão da 
qualidade aplicadas na empresa. Por meio da análise documental, verificou-se que a companhia adota, ao menos, três práticas principais de GQ. O Quadro 3 apresenta o detalhamento delas.

\section{Quadro 3: Práticas de GQ adotadas pela empresa de TI}

\begin{tabular}{|c|c|}
\hline Prática & Descrição resumida \\
\hline $\begin{array}{l}\text { Times de } \\
\text { qualidade }\end{array}$ & $\begin{array}{l}\text { A empresa dispõe, em sua estrutura organizacional, de duas } \\
\text { áreas de referência: o Escritório de Projetos (PMO) e a Área de } \\
\text { Qualidade (QA). A existência desses times evidencia a preocu- } \\
\text { pação e comprometimento da direção com os processos de GQ, } \\
\text { o que, segundo Crosby (1979), Campos (1999) e Batista (2008), } \\
\text { representa o primeiro passo para a implantação de qualquer } \\
\text { sistema relacionado à qualidade. }\end{array}$ \\
\hline $\begin{array}{l}\text { Guias de } \\
\text { referências } \\
\text { mundiais }\end{array}$ & $\begin{array}{l}\text { Tendo como foco o gerenciamento de projetos de software e a } \\
\text { entrega de produtos, serviços e soluções de excelência, o PMO } \\
\text { adota boas práticas dos seguintes guias: } \\
\text { Project Management Body of Knowledge (PMBOK }{ }^{\circledR} \text { ): considerado a } \\
\text { base do conhecimento sobre gestão de projetos; } \\
\text { Rational Unified Process (RUP): focado na sinalização de tarefas } \\
\text { e responsabilidades e pontos de decisão no desenvolvimento de } \\
\text { software; } \\
\text { Scrum ou do eXtreme Programing (XP): aplicado para a elimina- } \\
\text { ção de práticas de controle inadequadas, concentrando a empre- } \\
\text { sa na essência do negócio. } \\
\text { Por sua vez, a Área de Qualidade atua na validação de proces- } \\
\text { sos, produtos e serviços em consonância com os requisitos pre- } \\
\text { vistos no MPS.BR. Atualmente, a empresa enquadra-se no Nível } \\
\text { G (menor nível de maturidade). } \\
\text { A utilização dessa prática revela o interesse não apenas em } \\
\text { melhorar o desenvolvimento de software, mas também os } \\
\text { processos internos e modelo de negócios. Tal cuidado encontra } \\
\text { respaldo em Koscianski e Soares (2007), segundo os quais ao } \\
\text { adotar o MPS.BR, a empresa poderá chegar a um nível inicial } \\
\text { de maturidade e capacidade com menor grau de esforço e de } \\
\text { investimento. }\end{array}$ \\
\hline $\begin{array}{l}\text { Normas } \\
\text { internas de } \\
\text { GQ }\end{array}$ & $\begin{array}{l}\text { A empresa possui documentos internos de qualidade, como o } \\
\text { descritivo operacional, no qual são detalhados os procedimentos } \\
\text { de trabalho utilizados pela unidade de fábrica de software. }\end{array}$ \\
\hline
\end{tabular}

Fonte: Elaborado pelos autores. 
No que tange ao segundo objetivo, referente à identificação das práticas de gestão do conhecimento adotadas pela empresa, percebe-se a existência de estímulos de socialização das informações e conhecimento entre os colaboradores. As principais ações de GC foram sintetizadas no Quadro 4.

\section{Quadro 4: Práticas de GC adotadas pela empresa de TI}

\begin{tabular}{|l|l|}
\hline Prática & Descrição resumida \\
\hline & $\begin{array}{l}\text { A empresa realiza: } \\
\text { Assembleias da diretoria para deliberação (todas as ter- } \\
\text { ças-feiras); } \\
\text { Encontro com gerentes e equipes de projetos para acom- } \\
\text { panhamento e troca de experiências (uma vez por sema- } \\
\text { na); } \\
\text { Reunião de balanço das atividades executadas, previsão } \\
\text { de novos projetos e definição de metas (a cada seis me- } \\
\text { ses). } \\
\text { Tais práticas relacionam-se com o processo de conver- } \\
\text { são do conhecimento defendido por Nonaka e Takeuchi } \\
\text { (1997), no qual um conhecimento gerado em reuniões } \\
\text { pode ser analisado, categorizado e configurado para gerar } \\
\text { novas informações para a empresa. }\end{array}$ \\
\hline $\begin{array}{l}\text { Acompanha- } \\
\text { mento diário } \\
\text { das equipes de } \\
\text { projetos }\end{array}$ & $\begin{array}{l}\text { Focada no saneamento de problemas emergenciais e no } \\
\text { levantamento de pontos de melhoria, tal ação está respal- } \\
\text { dada em Batista (2008), que menciona que o compartilha- } \\
\text { mento de conhecimento por meio do feedback apresenta-se } \\
\text { como fator de mudança, melhoria do desempenho das } \\
\text { tarefas e construção coletiva. }\end{array}$ \\
\hline $\begin{array}{l}\text { Comunidades de } \\
\text { práticas }\end{array}$ & $\begin{array}{l}\text { Utilizada para nivelamento do conhecimento e execução } \\
\text { de projetos, no qual são montadas equipes de até três pes- } \\
\text { soas de diferentes áreas para a troca de experiências. Essa } \\
\text { prática encontra-se alinhada à Bejarano et al. (2006). }\end{array}$ \\
\hline $\begin{array}{l}\text { Aprendizagem } \\
\text { organizacional e } \\
\text { mentoring }\end{array}$ & $\begin{array}{l}\text { Utilizada principalmente para novos colaboradores, essa } \\
\text { prática tem como objetivo o compartilhamento de conhe- } \\
\text { cimento acerca da organização, posto que, nos primeiros } \\
\text { três meses, todos atuam em todas as áreas da empresa. } \\
\text { Nesse sentido, tais ações encontram-se alinhadas aos tra- } \\
\text { balhos de Soltero (2003) e Francini (2002). }\end{array}$ \\
\hline
\end{tabular}


continuação do Quadro 4: Práticas de GC adotadas pela empresa de TI

\begin{tabular}{|l|l|}
\hline Prática & Descrição resumida \\
\hline $\begin{array}{l}\text { Divulgação e } \\
\text { comunicação } \\
\text { interna }\end{array}$ & $\begin{array}{l}\text { Por meio de painéis de divulgação, ambiente de e-mail } \\
\text { corporativo e comunicação informal via hangouts e grupos } \\
\text { no whatsapp, tais ações nivelam as informações a todos os } \\
\text { colaboradores e incentivam a geração de novas ideias e } \\
\text { projetos, remetendo à prática de comunicação institucio- } \\
\text { nal defendida por Medeiros (1998). }\end{array}$ \\
\hline $\begin{array}{l}\text { Comunicação } \\
\text { com clientes e } \\
\text { parceiros }\end{array}$ & $\begin{array}{l}\text { A empresa divulga informações sobre produtos e serviços } \\
\text { por meio de blog institucional e redes sociais; tais práticas } \\
\text { estão alinhadas aos portais corporativos citados por Rey- } \\
\text { nols e Koulopoulos (1999) e Francini (2002). }\end{array}$ \\
\hline Capacitações & $\begin{array}{l}\text { Orientada com base nas demandas dos clientes, em um } \\
\text { primeiro momento, efetiva-se uma avaliação das compe- } \\
\text { tências internas da equipe; caso os membros da empresa } \\
\text { não as possuam, são promovidas ações de capacitação na } \\
\text { área deficiente. Desse modo, essa atividade encontra-se } \\
\text { respaldada em Éboli (2005) e seu conceito de educação } \\
\text { corporativa, e em Giacobbo } \text { et al. (2005) no que tange à } \\
\text { gestão por competências. }\end{array}$ \\
\hline
\end{tabular}

Fonte: Elaborado pelos autores.

Nesse contexto, segundo relatórios gerenciais da organização, a adoção do conjunto dessas práticas relacionadas à GQ e GC fez com que $95 \%$ dos projetos fossem executados no prazo e custo previstos, configurando assim alto nível de atendimento das soluções contratadas. Logo, percebe-se que a empresa tem investido na criação de um ambiente propício à troca de informações, ao conhecimento e à melhoria contínua, representando o que Paladini (2005) chama de perspectiva estratégica da qualidade.

Na sequência, visando a identificar pontos de convergência existentes entre os elementos da GC e GQ, terceiro objetivo deste estudo, realizou-se estatística descritiva por meio de análise inferencial das dimensões previstas no modelo teórico-prático de Batista (2008). Desse modo, em um intervalo de 1 a 5, as médias gerais variaram entre 2,72 e 3,77, conforme detalhado na Tabela 1. 
Em princípio, percebe-se que nenhuma dimensão atingiu média próxima ao "maior valor possível", representado pela nota 5, tendo sido atribuída à dimensão "processos" a melhor avaliação, alcançando $75 \%$ do grau máximo, e ao constructo "sociedade" o pior desempenho (54\% do grau máximo).

Tabela 1: Média geral das dimensões relacionados à interface de GC e GQ

\begin{tabular}{l|l|l|l|l|l|l|l}
\hline $\begin{array}{l}\text { Lide- } \\
\text { rança }\end{array}$ & $\begin{array}{l}\text { Estra- } \\
\text { tégia e } \\
\text { planos }\end{array}$ & $\begin{array}{l}\text { Clien- } \\
\text { tes }\end{array}$ & $\begin{array}{l}\text { Socieda- } \\
\text { de }\end{array}$ & $\begin{array}{l}\text { Informa- } \\
\text { çôes e } \\
\text { conheci- } \\
\text { mento }\end{array}$ & $\begin{array}{l}\text { Pes- } \\
\text { soas }\end{array}$ & $\begin{array}{l}\text { Pro- } \\
\text { cessos }\end{array}$ & $\begin{array}{l}\text { Resul- } \\
\text { tados }\end{array}$ \\
\hline 3,75 & 3,59 & 3,61 & 2,72 & 3,37 & 3,54 & 3,77 & 3,50 \\
\hline
\end{tabular}

Fonte: Elaborado pelos autores.

No que tange ao constructo "liderança", percebe-se que a variável "análise de desempenho como direção da tomada de decisões para aumentar a satisfação das partes interessadas" foi a mais bem avaliada, alcançando índice de $81 \%$. Esse comprometimento da empresa com a utilização de conhecimentos atuais para gerar novos valores organizacionais, de modo a satisfazer aos clientes, configura-se como a base da GQT na empresa, encontrando ainda respaldo em Deming (1986) e Campos (1999).

Por outro lado, o atributo "as decisões tomadas, após a análise de desempenho, são compartilhadas com as pessoas do nível operacional" recebeu a menor média. Isso indica que o processo interno de compartilhamento das informações demanda atenção, uma vez que Juran (1989) aponta que, para que um sistema de qualidade tenha resultados, é necessário transferir os planos resultantes do planejamento para as pessoas que atuam no nível operacional. Desse modo, depreende-se que as práticas de GC utilizadas atualmente não vêm desempenhando o papel esperado. Sugere-se, nesse caso, a designação de colaboradores para atuarem como propagadores do conhecimento, estimulando a divulgação das informações e criando uma cultura de comunicação. A Figura 1 apresenta as médias de cada atributo contido na dimensão "liderança". 
Figura 1: Média das variáveis da dimensão "liderança" em uma escala de 1 a 5

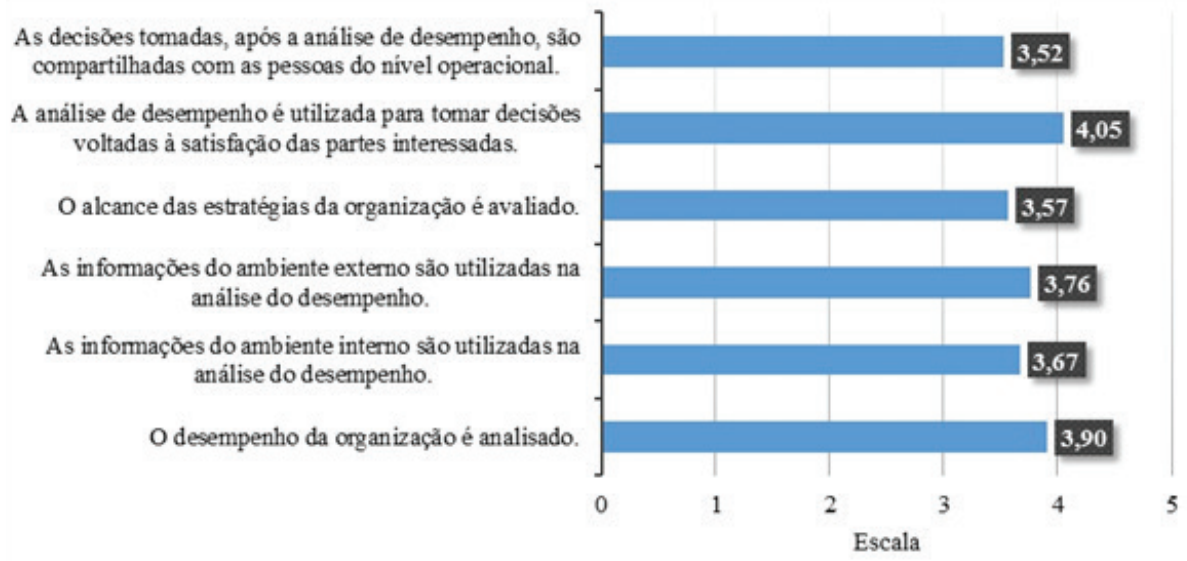

Fonte: Elaborado pelos autores.

Quanto à dimensão "estratégias e planos", detalhada na Figura 2 , a nota mais alta reflete a preocupação da empresa com o ambiente externo para a definição de suas estratégias. Para melhor posicionamento no mercado, esse olhar é fundamental; contudo, como detalhado no constructo anterior, não se pode abandonar a análise e compartilhamento dessas informações com a equipe de trabalho.

O critério mais baixo nesse item refere-se à "definição de indicadores para implementação de estratégias". Nesse cenário, verifica-se que a inexistência ou baixo nível de indicadores dificulta a avaliação do cumprimento das metas empresariais. Para otimizar e facilitar a mensuração desses ativos, recomenda-se maior envolvimento e participação dos colaboradores no processo estratégico e na construção de indicadores. 
Figura 2: Média das variáveis da dimensão "estratégias e planos" em uma escala de 1 a 5

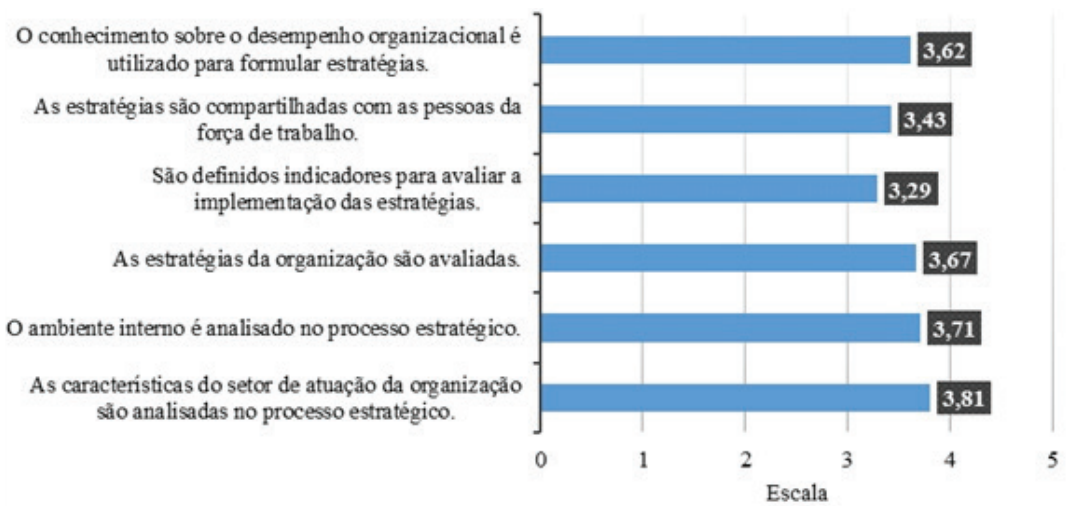

Fonte: Elaborado pelos autores.

O constructo "clientes", detalhado na Figura 3, demonstra a preocupação da empresa com o principal item avaliado pelos autores de GQ (CAMPOS, 1999; DEMING, 1986), no qual a maior nota está na identificação e atendimento das demandas dos clientes. No segmento de TI, esse critério é altamente relevante, posto que a incompreensão dos requisitos e expectativas conduzem à não aceitação do produto e/ou serviço ou à criação de funcionalidades desnecessárias, reduzindo o nível de satisfação da empresa no mercado.

Figura 3: Média das variáveis da dimensão "clientes" em uma escala de 1 a 5

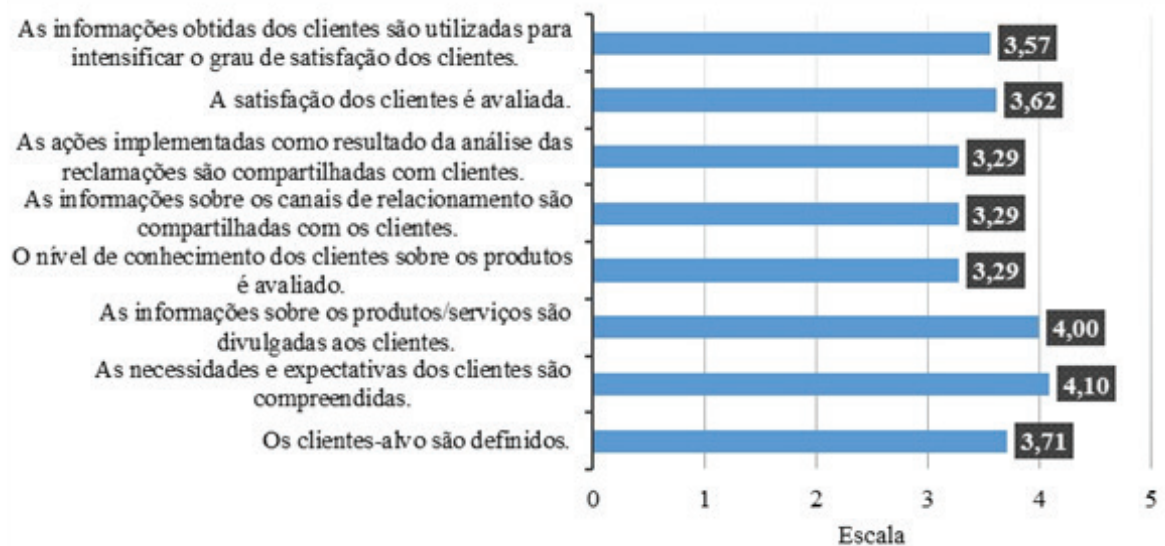

Fonte: Elaborado pelos autores. 
Contudo, nessa dimensão, percebe-se um espaço para melhoria do relacionamento com o cliente, uma vez que a nota máxima (5) não foi atingida em nenhum dos critérios. Portanto, ações como disponibilizar mecanismos e canais de relacionamento formais e informais, avaliar periodicamente o nível de conhecimento e satisfação quanto aos produtos e serviços e solucionar rapidamente problemas oriundos de reclamações podem ser adotadas pela empresa de modo a otimizar o atendimento aos consumidores.

Por sua vez, no constructo "pessoas", verifica-se que as demandas de capacitação são identificadas a cada novo projeto, focando as competências existentes e buscando estabelecer equipes complementares para difusão do conhecimento. Nas áreas deficitárias, as necessidades são identificadas e ações de capacitação e repasse dos conhecimentos promovidas. Tais constatações encontram respaldo em Giacobbo et al. (2005), que afirmam que a implementação de planos com o objetivo de desenvolver competências específicas necessárias aos executivos, equipes ou áreas é fundamental para a GC e a GQ.

Entretanto, surge o alerta à empresa para verificar fatores como o tratamento de riscos relacionados à saúde ocupacional, que obtiveram a média mais baixa da dimensão. Em empresas de TI, normalmente os colaboradores permanecem longos períodos sentados em frente a uma tela; nesse caso, requisitos de ergonomia, iluminação e outros devem ser considerados pela companhia com vistas a propiciar um ambiente saudável para a equipe. A Figura 4 apresenta as médias de cada um dos atributos na dimensão "pessoas".

.No que tange à dimensão "sociedade", observa-se que sete variáveis apresentaram médias inferiores a 3 pontos, indicando que a comunidade ainda não é considerada na implementação das estratégias de GC e GQ. Nesse caso, depreende-se que, assim como a empresa não considera relevante a sociedade, a recíproca pode ser verdadeira. Logo, identifica-se uma lacuna de marketing a ser trabalhada, posto que o conhecimento da sociedade sobre a empresa pode atrair novos clientes e estimular o desenvolvimento econômico, social e ambiental da região (BATISTA, 2008). A Figura 5 apresenta as médias em relação a cada atributo dessa dimensão. 
Figura 4: Média das variáveis da dimensão Pessoas em uma escala de 1 a 5

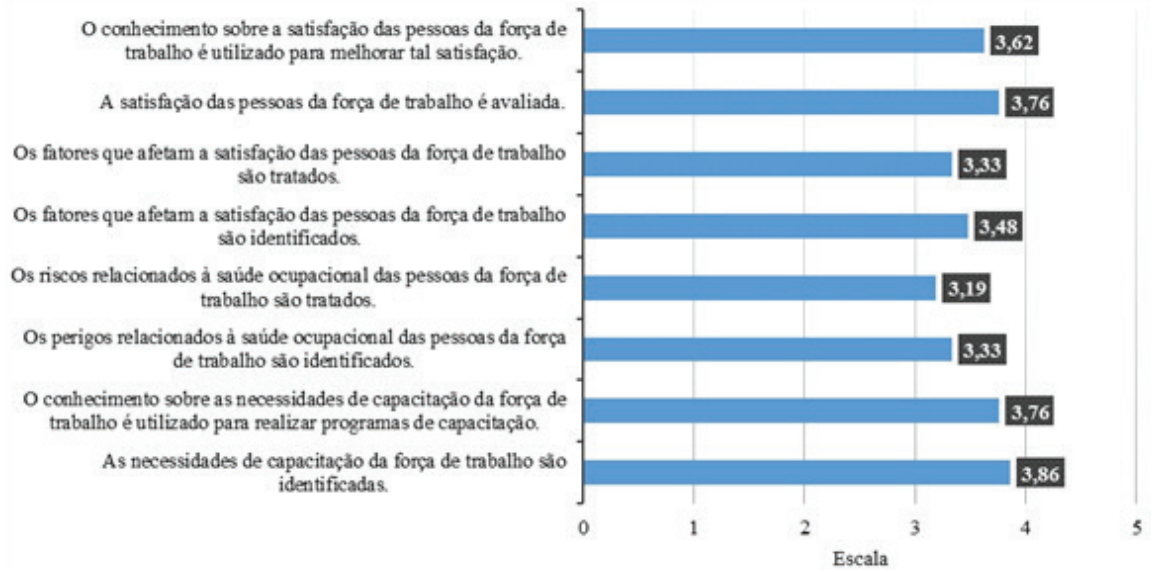

Fonte: Elaborado pelos autores (2016).

Figura 5: Média das variáveis da dimensão "sociedade" em uma escala de 1 a 5

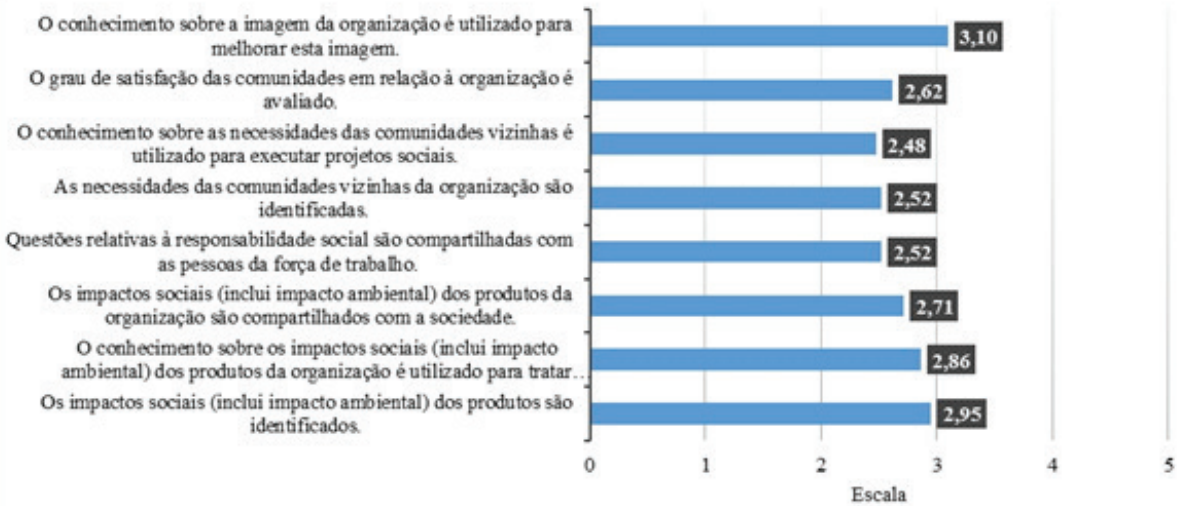

Fonte: Elaborado pelos autores.

A dimensão "informações e conhecimento" apresenta uma tendência da empresa em comparar suas informações com as de outras, a qual pode ser configurada em benchmarking (SPENDOLINI, 1994) ou melhores práticas (O’DELL; GRAYSON, 2000). Nesse aspecto, percebe-se que a companhia analisada busca melhorar o nível gerencial e maturidade por meio de guias referenciais como o MPS.BR e PMBOK ${ }^{\circledR}$. Todavia, para otimizar esse constructo, ela 
precisa identificar e avaliar os ativos intangíveis (marca, sistemas e processos), já que, no mercado de TI, esse critério representa o diferencial, o qual é relevante para determinar o seu valor. Na Figura 6, evidenciam-se as médias dos atributos dessa dimensão.

Figura 6: Média das variáveis da dimensão "informações e conhecimento" em uma escala de 1 a 5

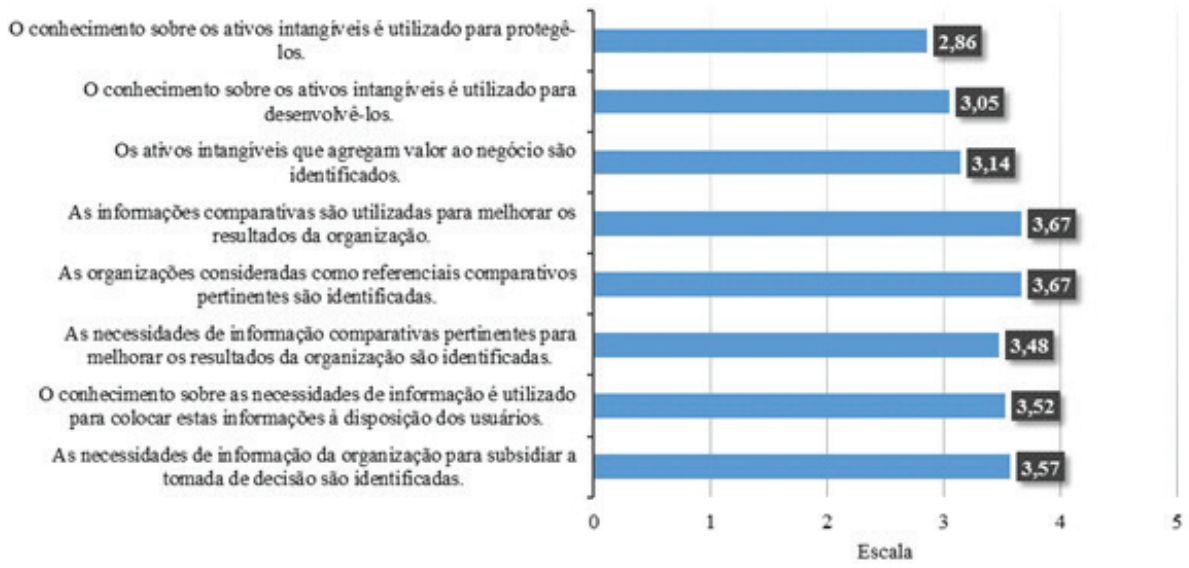

Fonte: Elaborado pelos autores.

Em relação à dimensão "processos", nota-se, na Figura 7, que o foco da empresa está na identificação daqueles que agreguem valor ao cliente. Sob esse enfoque, a existência de uma boa equipe não é suficiente; para obter maior eficiência e eficácia são necessários processos bem definidos, aliados às competências para executá-los. Todavia, a nota mais baixa diz respeito à medição do desempenho dos processos internos; nesse caso, sugere-se a implantação de métodos de mensuração, para os quais serão necessários a participação e o acompanhamento dos colaboradores. Com isso, esperam-se aumento da credibilidade e percepção de valor pelo cliente, gerando o que Francini (2002) define como qualidade. 
Figura 7: Média das variáveis da dimensão "processos" em uma escala de 1 a 5

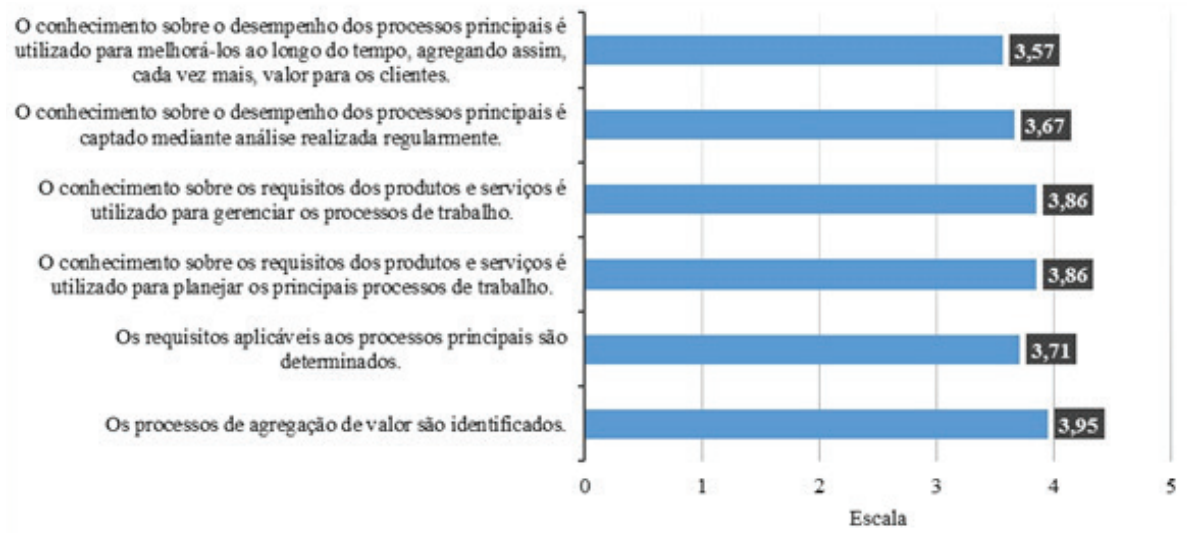

Fonte: Elaborado pelos autores.

Por fim, no constructo "resultados", ilustrado na Figura 8, verifica-se que as duas maiores notas obtidas têm relação direta com práticas da melhoria contínua dos processos - um dos pré-requisitos da GQ - e estão intimamente ligadas ao atendimento pleno das necessidades dos clientes. Tal constatação está amparada em Deming (1986), que defende que a implementação da gestão da qualidade tem como objetivo final a satisfação do cliente por meio da melhoria contínua dos processos, produtos e serviços.

Figura 8: Média das variáveis da dimensão "resultados" em uma escala de 1 a 5

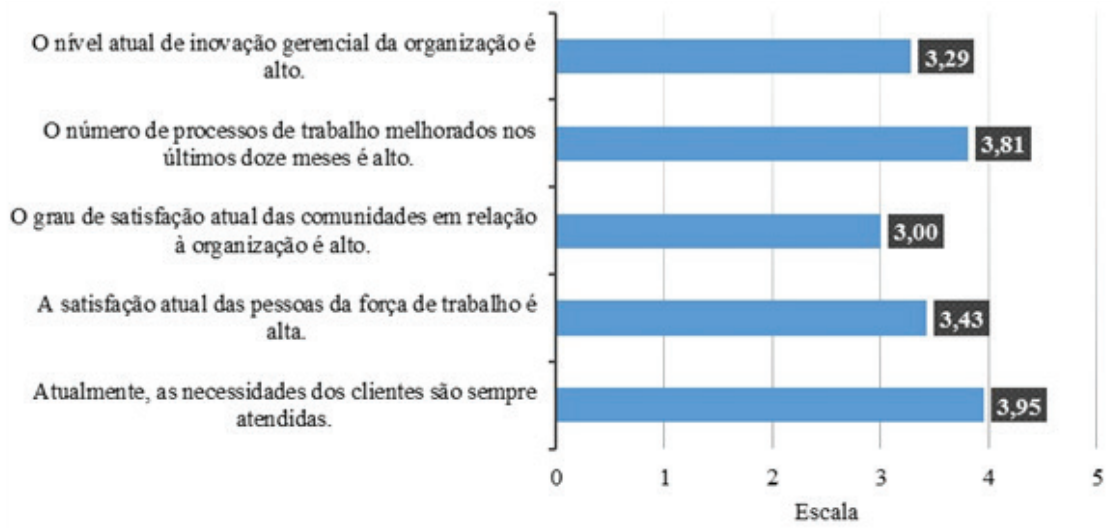

Fonte: Elaborado pelos autores. 
Em linhas gerais, constata-se que a empresa de TI estudada vem desenvolvendo boas práticas relacionados à GC e à GQ, as quais, muitas vezes, se sobrepõem. Todavia, verifica-se também que a companhia precisa rever estratégias e promover ações mais afirmativas relacionadas à comunicação interna e à percepção da sociedade como fator relevante de desenvolvimento. Isso permitirá que o compartilhamento das informações, a aprendizagem e o capital intelectual da empresa sejam aplicados integralmente no sistema de qualidade, conduzindo a organização para melhor aproveitamento do potencial humano e um desempenho mais satisfatório junto aos clientes.

\section{CONSIDERAÇões FINAIS}

Apesar de a GC e a GQ serem práticas gerenciais bastante difundidas, ainda são raros os estudos relacionados à interface desses elementos como determinantes no desempenho organizacional. Diante disso, este estudo objetivou responder qual a relação entre elas em uma empresa de TI de Foz do Iguaçu, segundo a opinião de seus colaboradores.

Complementarmente, foram estabelecidos três objetivos específicos. Os dois primeiros, referentes à identificação das práticas de GC e GQ, foram baseados na análise documental e estudo de caso. Desse modo, foram identificadas três ações de gestão da qualidade (times de qualidade, guias referenciais e normatização interna) e sete de gestão do conhecimento (reuniões, acompanhamento diário, comunidades de práticas, aprendizagem organizacional, comunicação institucional, relacionamento com clientes e capacitações).

Para o terceiro objetivo de identificar os pontos de convergência entre a GC e GQ, utilizou-se instrumento de pesquisa extraído do modelo teórico-prático de Batista (2008), o qual considerou oito dimensões: liderança; estratégia e planos; clientes; sociedade; informações e conhecimento; pessoas; processos; e resultados. O questionário, aplicado via formato eletrônico, teve adesão de 21 colaboradores em um total de 26.

Em relação às dimensões, percebeu-se um equilíbrio entre elas, uma vez que variaram entre 2,72 e 3,77. Em escala decrescente, foram melhor pontuados os constructos "processos", "liderança", "clientes", "estratégia e planos", "pessoas", "resultados", "informa- 
ções e conhecimento" e "sociedade". Nesse cenário, verificou-se o desenvolvimento tanto de práticas de GC quanto de GQ, as quais se sobrepõem continuamente e são complementares, haja vista que estimulam o compartilhamento das informações, aprendizagem, melhoria no desenvolvimento de processos, produtos e serviços e do ciclo de gestão empresarial. Entretanto, o elo mais fraco na convergência desses elementos diz respeito à comunicação.

Internamente, percebeu-se certo nível de desconhecimento acerca das práticas de GC; nesse sentido, depreende-se a necessidade de implementação de práticas mais sólidas e contínuas para divulgar as estratégias empresarias. Sob esse enfoque, sugere-se, por exemplo, a adoção de ações como: i) designação de equipe interna para atuar como propagadora do conhecimento, estimulando a divulgação das informações e criando uma cultura de comunicação; e ii) envolvimento e participação dos colaboradores no planejamento estratégico e na construção e acompanhamento de indicadores para mensurar ativos tangíveis e intangíveis (marca, sistemas e processos). Tais práticas estimularão os colaboradores a participarem ativamente do processo decisório, da geração e compartilhamento das informações e, consequentemente, da melhoria da gestão e desempenho organizacionais.

No campo externo, verificou-se que o nível de conhecimento e reconhecimento da sociedade ainda não é considerado na estratégia organizacional. Desse modo, recomenda-se a realização de ações externas dirigidas à divulgação dos resultados e dos benefícios provocados pela empresa nos campos sociais, científicos, tecnológicos e econômicos da região. Além disso, ações como: i) disponibilizar aos clientes mecanismos e canais de relacionamento formais e informais; ii) avaliar periodicamente o nível de conhecimento e satisfação quanto aos produtos e serviços; e iii) solucionar rapidamente problemas oriundos de reclamações; podem ser adotadas pela companhia de modo a otimizar o atendimento aos consumidores e aproximar a sociedade. Tais práticas serão fundamentais para aumentar o valor da marca e poderão, em longo prazo, representar a sustentabilidade do negócio.

Nesse contexto, de modo geral, considera-se que este estudo possibilita à empresa estudada identificar seus pontos fortes, bem 
como aqueles ainda a desenvolver, facilitando o conhecimento sobre ela mesma e permitindo adequações das práticas gerenciais. Caso as considerações tecidas nesta pesquisa sejam implementadas, depreende-se que será possível maior alinhamento das práticas de GC e GQ, vislumbrando melhor desempenho e maturidade organizacionais.

Todavia, como fator limitador do estudo constata-se o corte transversal da pesquisa, com avaliação ocorrida em um único momento. Nesse caso, como sugestão para trabalhos futuros recomenda-se a realização de estudos longitudinais com vistas a analisar possíveis variações quanto às práticas de GC e GQ adotadas pela empresa ao longo do tempo, verificando se houve melhoria do desempenho, especialmente nas dimensões organizacionais com médias mais baixas. Além disso, considerando que o modelo GCFQ proposto por Batista (2008) possui aplicabilidade teórica e prática, sugere-se sua utilização por outras companhias de TI ou de outros segmentos para avaliar a interface entre a gestão do conhecimento e a da qualidade.

\section{REFERÊNCIAS}

ALMACINHA, J. A. Introdução ao conceito de normalização geral e sua importância na engenharia. Texto de Apoio às Disciplinas de Desenho Técnico (LEM) e de Desenho Industrial I (LGEI). Porto: FEUP, 2005.

ANDRADE, M. M. de. Como preparar trabalhos para cursos de pós-graduação: noções práticas. 5. ed. São Paulo: Atlas, 2002.

BATISTA, F. F. Proposta de um modelo de gestão do conhecimento com foco na qualidade. 287 f. Tese (Doutorado em Ciência da Informação) - Universidade de Brasília, Brasília, 2008.

BENNET, A.; BENNET, D. Organizational survival in the new world: the intelligent complex adaptative system: a new theory of the firm. Burlington: Elsevier, 2004.

BEJARANO, V. C. et al. Equipes e comunidades de prática como estruturas complementares na gestão do conhecimento organizacional. J. Technol. Manag. Innov, Santiago, v. 1, issue 3, p. 100-106, 2006.

CAMPOS, V. F. TQC: Controle da Qualidade Total (no estilo japonês). Belo Horizonte: Fundação Christiano Ottoni, 1999.

CANONGIA, C. et al. Foresight, inteligência competitiva e gestão do conhecimento: instrumentos para a gestão da inovação. Gestão \& Produção, v. 11, n. 2, p. 231-38, maio/ago. 2004.

CANTNER, U.; JOEL, K.; SCHMIDT, T. The effects of knowledge management on innovative success: an empirical analysis of German firms. Research Policy, Amsterdã, v. 40, n. 10, p. 1453-1462, 2011. 
CARDOSO, V. C.; MORETO, D.; SILVA, L. R. O. Mapeamento de conhecimentos através de uma abordagem por processos como alternativa para a formulação de programas de capacitação. In: ENCONTRO NACIONAL DE ENGENHARIA DE PRODUÇÃO, XXI., 19-20 out. 2001, Salvador. Anais... Salvador: ENGEP, 2001.

CIERCO, A. A. et al. Gestão da qualidade. Rio de Janeiro: FGV, 2003.

CLARKE, S. The impact of knowledge management information on management practice. Information Management, Overland Park, v. 19, n. 3-4, p. 16-17, 2006.

CROSBY, P. B. Quality is free: the art of making quality certain. New York: McGraw-Hill, 1979.

CUNHA, I. B. de A.; DIAS, K. J. A. N.; RESENDE JUNIOR, J. H. C. Dificuldades encontradas na implementação MPS.BR nível G: estudo de caso. E-xacta, Belo Horizonte, v. 4, n. 3, p. 19-35, 2011.

DALKIR, K. Knowledge management in theory and practice. Burlington: Elsevier, 2005.

DAVENPORT, T. H. Ecologia da informação: por que só a tecnologia não basta para o sucesso na era da informação. São Paulo: Futura, 1998.

DAVENPORT, T. H.; PRUSAK, L. Conhecimento Empresarial: como as organizações gerenciam o seu potencial intelectual. 9. ed. Rio de Janeiro: Campus, 2003.

DEMING, W. E. Out of the crisis. Cambridge: Massachusetts Institute of Technology, 1986.

ÉBOLI, M. O papel das lideranças no êxito de um sistema de educação corporativa. RAE - Revista de Administração de Empresas, São Paulo, v. 45, n. 5, p. 118-122, out./dez. 2005.

FRANCINI, W. S. A gestão do conhecimento: conectando estratégia e valor para a empresa. RAE-Eletrônica, São Paulo, v. 1, n. 2, p. 1-16, jul./dez. 2002.

FNQ - FUNDAÇÃO NACIONAL DA QUALIDADE. Modelo de Excelência da Gestão® (MEG) - Guia de Referência de Excelência da Gestão. São Paulo: FNQ, 2016.

GIACOBBO, E. M. et al. Mapeamento de Competências: o caso da Cia. Iguaçu de Café Solúvel. In: ENCONTRO NACIONAL DE ENGENHARIA DE PRODUÇÃO, XXV., 2005. Anais... Porto Alegre: ENGEP, 2005.

KLOTZ, L. et al. The impact of process mapping on transparency. International Journal of Productivity and Performance Management, Bingley, v. 57, n. 8, p. 623-36, 2008.

KOSCIANSKI, A.; SOARES, M. dos S. Qualidade de Software. São Paulo: Editora Novatec, 2007. KURTA, V. L.; CARVALHO, H. G.; KOVALESKI, J. L. A gestão do conhecimento dentro da filosofia do Controle da Qualidade Total (TQC). In: ENCONTRO NACIONAL DE ENGENHARIA DE PRODUÇÃO, XXIV., 2004, Florianópolis. Anais... Porto Alegre: ABEPRO, 2004.

JURAN, J. M. Juran on leadership for quality: an executive handbook. New York: The Free Press, 1989.

MARCONI, M. de A.; LAKATOS. E. M. Fundamentos de metodologia científica. 5. ed. São Paulo: Atlas, 2003.

MARTINS, R. A.; COSTA NETO, P. L. de O. Indicadores de desempenho para a gestão da qualidade total: uma proposta de sistematização. Gestão \& Produção, São Carlos, v. 5, n. 3, p. 298-311, dez. 1998. 
MEDEIROS, J. B. Redação empresarial. 3. ed. São Paulo: Atlas, 1998.

MEYRS, J. H.; REYNOLDS, W. H. Gerência do marketing e comportamento do consumidor. Petrópolis: Ed. Vozes, 1972.

MINOR, M. Coaching e aconselhamento: um guia prático para gerentes. Rio de Janeiro: Qualitymark, 1997.

NONAKA, I.; TAKEUCHI, H. Criação do conhecimento na empresa: como as empresas japonesas geram a dinâmica da inovação. São Paulo: Campus, 1997.

O'DELL, C.; GRAYSON JR., C. J. Ah... se soubéssemos antes o que sabemos agora: as melhores práticas gerenciais ao alcance de todos. São Paulo: Futura, 2000.

PALADINI, E. P. Perspectiva Estratégica da Qualidade. In: CARVALHO, M. M. et al. (Org.). Gestão da Qualidade: teoria e casos. Rio de Janeiro: Elsevier, 2005. p. 25-84.

PROBST, G.; RAUB, S.; ROMHARDT, K. Gestão do conhecimento: os elementos construtivos do sucesso. Porto Alegre: Bookman, 2002.

REYNOLS, H.; KOULOPOULOS, T. Enterprise knowledge has a face. Intelligent Enterprise, New York, v. 2, n. 5, p. 29-34, mar. 1999.

SENGE, P. M. A quinta disciplina: arte, teoria e prática da aprendizagem. 15. ed. São Paulo: Editora Best-Seller, 1990.

SILVA, N. O. A gestão do conhecimento no contexto dos Sistemas de Qualidade (ISO 9001, PNQ e PGQP). In: WORKSHOP BRASILEIRO DE INTELIGÊNCIA COMPETITIVA E GESTÃO DO CONHECIMENTO, 3., 2002. Anais... São Paulo: SBGC, 2002.

SOLTERO, A. P. Gestão do Conhecimento na solução de problemas de gestão da Qualidade. In: TERRA, J. C. C.; KRUGLIANSLAS, I. (Org.). Gestão do conhecimento em pequenas e médias empresas. Rio de Janeiro: Ed. Campus, 2003. p. 81-104.

SPENDOLINI, M. J. Benchmarking. São Paulo: Makron Books, 1994.

SVEIBY, K. A knowledge-based approach to performance excellence. [On-line]. 2001. Disponível em: <http://www.sveiby.com/articles/kbasedbaldrige.htm>. Acesso em: 20 maio 2016.

VALLS, V. M. A sinergia entre a gestão da qualidade e do conhecimento. Revista Banas Qualidade, São Paulo, v. 151, n. 14, p. 38-39, dez. 2004.

YIN, R. Case study research: design and methods. 2. ed. Thousand Oaks: Sage, 1994.

Recebido em: 26-12-2016

Aprovado em: 24-4-2017

Avaliado pelo sistema double blind review.

Editor: Elmo Tambosi Filho

Disponível em http://mjs.metodista.br/index.php/roc 